\title{
Religião e política em debate nos anos da Unidad Popular: a experiência dos Cristianos por el Socialismo
}

\author{
Eduardo Matheus de Souza Dianna ${ }^{1}$
}

RAMMINGER, Michael. Éramos iglesia... en medio del Pueblo: El legado de los Cristianos por el Socialismo en Chile 1971 - 1973. Trad. Manuel Ossa Bezanilla. Santiago: LOM ediciones, 2019.

Resenha recebida em: 14/04/2020

Resenha aprovada para publicação em: 06/05/2020

Próximo de completar 50 anos em setembro de 2020, o processo de transição do capitalismo ao socialismo no Chile, proposto pela Unidad Popular (UP) de Salvador Allende Gossens, recebe mais uma contribuição teórica. A obra de Michael Ramminger - publicada originalmente em alemão sob o título “...Wir waren Kirche ... inmitten der Armen: Das Vermächtnis der Christen für den Sozialismus in Chile von 1971-1973” - oferece um aporte significativo para a compreensão do desenvolvimento do catolicismo de esquerda chileno nos anos 1960 e 1970.

O autor busca reconstituir a experiência histórica dos Cristianos por el Socialismo $(\mathrm{CpS})$ por meio de diversos temas que permearam seu curto período de atuação, oficialmente entre setembro de 1971 a setembro de 1973. Seu propósito é o de "devolver a atualidade da história dos Cristãos pelo Socialismo" (2019, p. 13), pois em sua interpretação, ao retomarem o tema, os pesquisadores à direita do espectro político e a Igreja Católica escrevem uma história a partir de seu próprio interesse, em geral, de deslegitimação do movimento. $\mathrm{O}$ empreendimento do autor vai na contramão dessa perspectiva: além de examinar as cartas circulares e as declarações

\footnotetext{
${ }^{1}$ Mestrando em História na Universidade Estadual Paulista "Júlio de Mesquita Filho" (UNESP/FCL - Assis). Título da pesquisa em andamento: "Entre Deus e a revolução: Cristianos por el Socialismo e o Chile de Allende". O presente trabalho foi realizado com apoio da Coordenação de Aperfeiçoamento de Pessoal de Nível Superior Brasil (CAPES) - Código de Financiamento 001. E-mail: ded-dianna@ hotmail.com.
} 
públicas, Ramminger, utiliza a metodologia da História Oral, para retomar a história dos CpS com a análise das narrativas da base, a partir da entrevista com ex-membros e simpatizantes do movimento.

O livro é dividido em 14 capítulos e trata de questões que, entre outras, contemplam a formação histórica dos $\mathrm{CpS}$; passando pelos embates político-teológicos em torno do pensamento Democrata Cristão, pela contradição social entre a hierarquia católica e os sacerdotes progressistas. Igualmente foram abordadas suas principais atividades, tais como a viagem a Cuba e a organização do Primeiro Encontro Internacional de Cristãos pelo Socialismo, ambos em 1972. A relação de apoio dos CpS com o movimento dos pobladores e com a classe trabalhadora em geral, no que diz respeito às suas reivindicações e lutas, também for debatida por Ramminger.

A atuação política e eclesial dos CpS, conferida pelas questões supramencionadas, mas também por suas discussões e debates públicos, demonstram que eram significativamente importantes para o contexto, em razão dos dilemas e desafios que o país vivenciava. Isso evidencia que o movimento não era somente uma corrente clerical no interior da Igreja, mas sim que estavam imbricados na história do país e comprometidos com o processo de transição em curso iniciado pela UP.

Nessa perspectiva, Ramminger sugere que o movimento era composto sobretudo por sacerdotes jovens, que trabalhavam e viviam em bairros pobres, por teólogos, estudantes e laicos. Essas pessoas, enquanto interlocutores dos $\mathrm{CpS}$, possuíam um interesse principal: articular politicamente aqueles que enxergavam os valores do projeto de uma sociedade socialista próximo aos valores cristãos, trilhando estratégias de lutas e participação que os colocassem na direção da construção de um sujeito ativo no âmbito das transformações estruturais experimentadas no Chile (2019, p. 47).

Atrelado a isso, objetivavam vincular o discurso religioso ao discurso político, de maneira que esses cristãos conseguissem - a partir de uma leitura crítica do Evangelho, voltada a diagnosticar os problemas cotidianos causados pelo capitalismo - associar ideologicamente a religião a um processo histórico de transformação mais longo, isto é, que analisassem a religião 
e o processo político de maneira vinculada e não separada. Essa premissa é uma das ideias fundamentais apresentadas por Löwy (2002), na qual sugere que sob o âmbito da Teologia da Libertação, o pobre passa de um sujeito passivo, digno de caridade e assistência, desconectado do campo da política, para um sujeito ativo, agente da transformação social.

Ramminger sustenta que os CpS tiveram alguns elementos históricos que contribuíram para seu surgimento: o primeiro deles, estabelecido no primeiro quarto do século $\mathrm{XX}$, mas que manteve relação direta na maneira com a qual a Igreja Católica atuou politicamente nas décadas posteriores, e que teria sido sua adaptação diante da nova realidade em virtude da separação com o Estado em 1925, concretizada pela promulgação da nova Constituição Política em setembro daquele ano. Isso obrigou a Instituição a se relacionar de maneira diferente com a sociedade, uma vez que não estava mais diretamente associada ao poder público, aproximandose da argumentação desenvolvida Giraudier (2015). O segundo elemento foi o impacto político da fundação do Partido Demócrata Cristiano (PDC), em 1957 - e suas divisões, que culminariam na formação de outros partidos de esquerda cristãos, como o Movimiento de Acción Popular Unitaria (MAPU) e a Izquierda Cristiana (IC) -, bem como o contexto econômico dos anos 1960, com as reformas iniciadas pelo governo democrata-cristão de Eduardo Frei, a partir de 1964. Por último, também nos anos 1960, o aggiornamento da Igreja iniciado pelo Concílio Vaticano II (1962 - 1965), mas sobretudo pelo pacto das Catacumbas (1965) e pela Segunda Conferência Geral do Episcopado Latino-americano (1968). Esses acontecimentos, que provocaram uma revisão no olhar social da Igreja e uma "reforma" na maneira do clero se relacionar com a sociedade, foram responsáveis pelo desenvolvimento dos $\mathrm{CpS}$ no Chile. Seu surgimento constitui-se, portanto, de uma resposta religiosa aos anseios dos novos tempos, tanto da sociedade quanto da Igreja em si.

Ramminger sublinha que os intelectuais dos CpS sustentaram que a utilização das Ciências Sociais e, explicitamente, a análise marxista do capitalismo não somente eram adequadas, mas sim necessárias para a compreensão real da situação de exploração no país e no continente. Logo, a "ação libertadora" não seria construída sem uma base teóricometodológica ou exclusivamente a partir da Bíblia. Para tal fim seria preciso recorrer à análise 
e às ferramentas da Sociologia - nesse caso da Sociologia Política, no que diz respeito aos conceitos de luta de classes, teoria da dependência, teoria do desenvolvimentismo, entre outros.

Desse ângulo, decorre o fato de que os CpS puderam analisar a sociedade e suas relações alicerçados sob a ótica do materialismo histórico dialético e não da perspectiva idealistahumanista, como é comum para os cristãos. Isso fez com que, tanto no Chile quanto no desenvolvimento do catolicismo social na América Latina, a filosofia escolástica fosse colocada de lado, tendo "perdido a validade" diante de análises mais estruturalmente fundamentadas. Nesse sentido, o apelo e a percepção da importância metodológica da Sociologia, já colocava os $\mathrm{CpS}$ em conflito ideológico com amplos setores da hierarquia católica, representada pela Conferencia Episcopal de Chile (CECH) e com os democrata-cristãos, em função de sua maneira de enxergar as relações sociais com base no "humanismo" cristão e da Doutrina Social da Igreja.

A partir da análise da documentação e da atuação da $\mathrm{CECH}$ no que diz respeito aos $\mathrm{CpS}$, Ramminger sugere a hipótese de que a Instituição estaria atravessada por contradições sociais. Assim, um dos elementos que mais influenciaram negativamente a relação de ambos, conforme o autor sustenta, foi justamente a indagação da hierarquia sobre a unidade do clero. Desde suas primeiras aparições e declarações públicas, os bispos consideravam a existência e as atividades desenvolvidas pelos CpS como uma afronta à sua autoridade e à unidade de seu corpo eclesial, sendo constantemente acusados de romperem com a harmonia da Instituição, sobretudo por idealizarem uma organização cristã paralela a oficial. No entanto, contrariando a acusação dos bispos, o autor defende que os CpS não possuíam essa intenção e ainda argumenta que movimento compreendeu a autonomia do político em relação ao aspecto religioso e que, por isso, seu objetivo não era o de formar organizações cristãs ou mesmo partidos políticos cristãos - para assim oferecerem uma "contribuição cristã específica" no processo de transformações que ocorria no Chile -, mas sim que seus membros pudessem se organizar e praticar sua ação política nos sindicatos, em iniciativas de vizinhos locais, em ocupações de terra, nas Juntas de Abastecimento, entre outras. Ou seja, o engajamento político dos $\mathrm{CpS}$ deveria ocorrer na medida em que seus membros integrassem os movimentos de luta pela libertação dos pobres e 
endossassem as organizações populares já existentes, compreendendo a possibilidade de articulação entre a fé cristã e o programa proposto pela UP, não o de afrontar diretamente a Igreja com outras organizações cristãs ou fundar uma "Igreja paralela".

Especificamente sobre o vínculo conflituoso entre a hierarquia católica e os $\mathrm{CpS}$, Ramminger demonstra que os bispos mantiveram uma relação de distanciamento e desaprovação pública ao movimento, na medida em que aprofundavam seu compromisso político e declaravam seu apoio ao socialismo. Os CpS, por sua vez, adotaram uma linha mais branda de críticas direcionadas à hierarquia. Segundo o autor, essa era uma estratégia de não enfrentamento em virtude de seu compromisso político bem definido e da conhecida reação negativa dos bispos. Por esse motivo, buscavam evitar conflitos diretos com a CECH de maneira a demonstrar que "eram Igreja" e que não tinham intenção de criar um organismo cristão paralelo ao oficial. No entanto, como o tempo revelou, essa estratégia de evitar críticas diretas não surtiu efeito. Pós-golpe, corroborando com a tese de Kallás (2008), na qual defende que a hierarquia cumpriu um papel de legitimação moral do golpe de Estado, Ramminger evidencia que 27 dos 30 bispos se sentiram "aliviados" com o ocorrido, pois, além de interromper o processo iniciado pela UP, recebiam respaldo político e social necessário para expulsarem os $\mathrm{CpS}$ da Igreja.

Os tópicos da militância política nos partidos estiveram presentes nos debates dos CpS, assim como as diversas táticas e estratégias da esquerda chilena. Ramminger é categórico ao afirmar que a política partidária não representou a realidade do movimento, isto é, de que havia poucos filiados aos partidos de esquerda da época, corroborando com a investigação de Fernández (1997). Não obstante, as discussões sobre essas possibilidades e o engajamento político dos membros fizeram com que evidentemente ocorressem algumas aproximações. Dessa maneira, de acordo Ramminger, havia uma orientação para que os membros do $\mathrm{CpS}$ nutrissem um apoio crítico em relação aos partidos, em virtude das "constelações de poder e dos conflitos de interesse" (2019, p. 159). Aos poucos militantes partidários, pediam atenção para que cada ação estivesse a "serviço do processo e não do desprestígio ou do poder de um partido" (2019, p. 160). 
No que se refere ao compromisso e a estratégia política, os $\mathrm{CpS}$ se colocaram mais próximos da IC e especialmente do Movimiento de Izquierda Revolucionaria (MIR) que dos partidos tradicionais de esquerda, como o Partido Comunista (PC) e o Partido Socialista (PS). Segundo Ramminger, a explicação para tal pode ser encontrada no juízo de que cada partido fazia "sujeito revolucionário" ou do "agente da revolução". Para o PC e para a ala mais conservadora do PS, a revolução no Chile devia ser orientada pelo operariado e pelos camponeses, seguindo as diretrizes do comunismo internacional. Por outro lado, o MIR delegava um importante papel aos "despossuídos", isto é, a massa de trabalhadores desempregados e pobres vivendo nos bairros periféricos, sobretudo nas habitações populares, as poblaciones. Além dos trabalhadores e camponeses, ao MIR caberia o papel de conscientizar e mobilizar essas pessoas em favor das transformações no país e principalmente na direção da construção do poder popular.

Os CpS, pela vivência dos seus sacerdotes nas poblaciones, pela evangelização e sua integração nas lutas e reivindicações cotidiana nesses espaços, enxergavam na estratégia desse último um processo mais plausível para a realidade latino-americana, em detrimento de uma conscientização restrita ao ambiente sindical e camponês. Além disso, o MIR e os CpS compartilhavam um juízo cético sobre as possibilidades reais do programa da UP, operando no interior de um sistema constitucional como se pretendia, para empreender transformações tão profundas no país. Entretanto, Ramminger afirma que essa proximidade de estratégias não mantinha relação direta com o MIR, mas sim com a vivência e experiência desses sacerdotes no ambiente das poblaciones. É possível que tenham aprofundado seu compromisso com as massas a partir da atuação do MIR, mas o fenômeno em si remonta a vivência com essas populações no interior de um movimento mais amplo no que se refere ao desenvolvimento do catolicismo social e da perspectiva da Teologia da Libertação no continente.

A obra também oferece uma contribuição significativa para refletir os CpS enquanto importantes interlocutores/atores políticos em um campo cuja unidade estava fragilizada. Segundo o autor, em seu Encontro Nacional ocorrido em novembro de 1972, cujas principais lideranças dos partidos de esquerda estavam presentes, coube aos $\mathrm{CpS}$ o papel de organização 
e mediação dos conflitos e estratégias, sobretudo entre o PC e o MIR, resultadas das distintas táticas postuladas em torno do projeto da UP. Enquanto moderadores desses dissensos, argumentavam que havia nas forças populares uma prontidão e um apelo pela unidade e que por isso ela era possível, mesmo por cima das discordâncias entre os partidos políticos. Assim, pela harmonia dos partidos e pela unidade das estratégias em direção a consolidação do projeto de um Chile socialista, os CpS solicitavam que as diferenças táticas fossem superadas. Dado o contexto em que o Encontro ocorreu ${ }^{2}$, o papel atribuído aos CpS manifesta seu prestígio junto aos partidos e a seus principais dirigentes. Confirma também a importância do espaço construído pelos cristãos no âmbito da política e do potencial mediador do $\mathrm{CpS}$ naquele momento, como sublinha Ramminger.

É compreensível que a proposta do livro seja a de analisar os CpS em seus desdobramentos mais imediatos no Chile, como no episódio mencionado acima. Contudo, o autor não teve uma pretensão mais acentuada em articular as ações do grupo em uma conjuntura político-eclesial mais ampla, uma vez que os pronunciamentos e ações dos CpS foram tomados em função de um sentimento de "defesa" do governo popular e do socialismo, concomitantemente ao cenário político. Dessa forma, embora o autor tenha procurado tratar os CpS em sua integralidade, é preciso uma leitura mais cuidadosa para que tenhamos uma compreensão mais aprofundada do comportamento político desempenhado pelo movimento. Também é possível afirmar que Ramminger menciona outros grupos de cristãos de esquerda de outros países latino-americanos, porém o faz de maneira breve e não os situa no interior de uma evolução processual do catolicismo social no continente, a partir dos princípios da incipiente Teologia da Libertação. Assim, a falta de contextualizações mais gerais, tanto no âmbito da política quanto da teologia - além conduzirem o leitor na direção de um entendimento no qual os CpS tomaram ações autônomas e isoladas, quando na verdade elas mantiveram vínculos

\footnotetext{
${ }^{2}$ Um mês após a greve de outubro, influenciados pela propaganda opositora ao governo da UP e pela crise econômica, uma parcela significativa do país parou. Como bem demonstrou Borges (2011), foi um momento em que as divergências entre as estratégias políticas do MIR e do PC se acentuaram de maneira irreparável. De um lado o MIR, mobilizando o movimento popular para que ocupassem as fábricas e continuassem a produção do país. Do outro o PC, mais conservador em relação a esse processo, alertando que tal movimento prejudicava a ordem e o legalismo do projeto da UP.
} 
estreitos com o campo político-teológico e suas demandas -, dão impressão de que, de certo modo, os CpS tenham sido um movimento singular na América Latina, o que de fato não ocorreu.

Como demonstrou Casals (2013), no Chile o anticomunismo é um fenômeno de longa data e desfrutou de uma contribuição católica ${ }^{3}$. Desse modo, outro elemento que a obra de Ramminger deixa de problematizar é justamente anticomunismo católico, sua relação com a Igreja e suas consequências negativas, sobretudo aquelas direcionadas aos CpS. Um exemplo nítido desse fenômeno e seu impacto social foram as campanhas anticomunistas da Igreja, desde os anos 1950, contra as coalizões de esquerda na política chilena. É nítido, portanto, que as ações de reprovação da hierarquia contra os CpS fizeram parte de um processo histórico mais amplo, que infelizmente não foram abordados por Ramminger.

A obra localiza os $\mathrm{CpS}$ chilenos como o produto final da associação de cristãos de esquerda no país que, já no final dos anos 1960, se organizavam em torno do movimento da Iglesia Joven - cujo objetivo era o de alertar contra a situação social e econômica do Chile, mas também sobre a necessidade de uma transformação na Igreja -, do grupo de los 80 , reunidos em meados abril de 1971 em torno da jornada sacerdotal sobre "La participación de los cristianos en la construcción del socialismo" e de um processo que remonta à formação dos "sacerdotes obreiros", isto é, de sacerdotes que se integravam à realidade do trabalho e de todas as dificuldades presentes na vida nas poblaciones.

Por fim, é importante dizer que a obra dimensiona o significado real e prático dos Cristianos por el Socialismo: um movimento amplo de sacerdotes e religiosos, sem regras fixas, de participação irrestrita, com uma variedade de pensamentos e estratégias de ação, no qual um grupo de cristãos com um assumido compromisso político e objetivo comuns, se reuniam em torno do objetivo principal: o debate pela construção do socialismo no Chile.

\footnotetext{
${ }^{3}$ Em sua tese de Doutorado, “Em guarda contra o perigo vermelho: o anticomunismo no Brasil (1917-1964)”, Rodrigo Patto Sá Motta (2002) sustenta que o fenômeno do anticomunismo não reside em um espectro político em específico, mas sim em um campo difuso a partir da lógica de diversos atores. Suas frentes podem ser encontradas no liberalismo, no nacionalismo e no catolicismo. As pesquisas de Marcelo Casals têm como foco principal as investigações sobre essas faces do anticomunismo no Chile.
} 


\section{Referências Bibliográficas}

BORGES, Elisa de Campos. ; Con la Unidad Popular ahora somos Gobierno! Experiência dos Cordones Industriales no Chile de Allende. Tese (Doutorado) - Universidade Federal Fluminense, Instituto de Ciências Humanas e Filosofia. Departamento de História, 2011.

CASALS, Marcelo. La "larga duración" del autoritarismo chileno. Prácticas y discursos anticomunistas camino al Golpe de Estado de 1973. Revista de Historia y Geografía, Santiago, n. 29, p. 31-54, 2013.

FERNÁNDEZ, David. "Cristianos por el Socialismo" en Chile (1971-1973). Aproximación histórica a través del testimonio oral. Studia Zamorensia, n.2, v.4, 1997.

GIRAUDIER, Élodie. Los católicos y la política en Chile en la segunda mitad del siglo XX. Revista del CESLA, Varsovia, n.18, pp. 213-237, 2015.

KALLÁS, Ana Lima. A paz social e a defesa da ordem: a Igreja Católica, o governo Allende e o golpe militar de 1973. Rio de Janeiro, 2008, 271f. Dissertação (Mestrado em História). Rio de Janeiro: UFRJ/IFCS, 2008.

LÖWY, Michael. A guerra dos deuses: religião e política na América Latina. Trad. Vera Lúcia Mello Joscelyne. Petrópolis: Vozes, 2000. 